\title{
Desain Katalog Digital Penunjang Informasi Dan Promosi Pada Sheen Production
}

\author{
Lusyani Sunarya ${ }^{* 1}$, Karunia Suci Lestari ${ }^{2}$, Zeiniati Cholishoh ${ }^{3}$ \\ ${ }^{1,2}$ Program Studi Teknik Informatika, Fakultas Sains dan Teknologi, Universitas Raharja \\ E-mail: ${ }^{* 1} \underline{\text { lusyani@ raharja.info }},{ }^{2} \underline{\text { suci@ raharja.info }},{ }^{3}$ zeiniati@ raharja.info
}

\begin{abstract}
Abstrak
Jasa Videografi dan Fotografi sangat diminati saat ini untuk acara seperti lamaran, pernikahan, ulang tahun, dan acara lainnya untuk mendokumentasikan moment-moment indah bersama orang tersayang. Semakin banyak peminat jasa videografi dan fotografi menyebabkan meningkatnya persaingan. Banyak cara juga yang dilakukan untuk bersaing menarik pelanggan dengan berbagai media promosi. Sheen Production sebelumnya masih bertemu langsung ke pelanggan yang berminat menggunakan jasanya, lalu memberikan katalog cetak untuk melihat paket-paket jasa yang ada pada Sheen Production. Hal ini dirasa kurang efektif, sehingga diperlukan sebuah media promosi berbentuk katalog digital, yang diharapkan dapat berpengaruh besar dalam menyampaikan pesan dan informasi secara efektif tanpa perlu mengeluarkan biaya untuk cetak katalog. Katalog digital sangat berfungsi dalam mendukung pemasaran atau promosi, untuk meningkatkan pelanggan baru. Dalam penelitian ini penulis menggunakan metode mind mapping untuk memudahkan penulis dalam mengingat suatu informasi utama. Lalu dalam perancangan desain dengan konsep desain meliputi layout kasar, layout komprehensif, serta final artwork. Untuk menghasilkan desain yang menarik, desain katalog digital ini dibuat dengan menggunakan aplikasi Adobe Photoshop CC 2019. Melalui media digital ini diharapkan dapat membantu Sheen Production dalam pemasaran jasa videografi dan fotografi dengan desain yang elegan dan detail informasi yang jelas untuk mudah dipahami oleh pelanggan.
\end{abstract}

Kata Kunci - Videografi, Fotografi, Media Promosi, Katalog

\begin{abstract}
Videography and Photography services are in great demand today for events such as applications, weddings, birthdays, and other events to document beautiful moments with loved ones. The increasing number of enthusiasts in videography and photography services causes increased competition. There are also many ways to compete to attract customers with various promotional media. Previously, Sheen Production still met directly with customers who were interested in using her services, then provided a printed catalog to see the service packages available at Sheen Production. This is considered ineffective, so we need a promotional media in the form of a digital catalog, which is expected to have a big influence in conveying messages and information effectively without having to pay for catalog printing. Digital catalogs are very useful in supporting marketing or promotion, to increase new customers. In this study, the writer used the mind mapping method to make it easier for the writer to remember the main information. Then in designing the design with a design concept including rough layout, comprehensive layout, and final artwork. To produce an attractive design, this digital catalog design was created using the Adobe Photoshop CC 2019 application. Through this digital media, it is hoped that it can help Sheen Production in marketing videography and photography services with an elegant design and clear detailed information that is easy for customers to understand.
\end{abstract}

Keywords - Videography, Photography, Promotional Media, Catalog 


\section{PENDAHULUAN}

Jasa Videografi dan Fotografi sangat diminati saat ini untuk acara seperti lamaran, pernikahan, ulang tahun, dan acara lainnya untuk mendokumentasikan moment-moment indah bersama orang tersayang. Semakin banyak peminat jasa videografi dan fotografi menyebabkan meningkatnya persaingan. Banyak cara juga yang dilakukan untuk bersaing menarik pelanggan dengan berbagai media promosi. Sheen Production bergerak pada penyedia jasa videografi dan fotografi yang beralamat di Komplek Sekertariat Negara RI Blok B1 No. 1 Keluruahan Panungganan Utara, Kecamatan Pinang, Kota Tangerang, 15143.

Studi kasus yang diambil dalam penelitian ini pada Sheen Production adalah untuk meningkatkan minat pelanggan untuk menggunakan jasanya. Sheen Production sebelumnya masih menggunakan cara bertemu langsung ke pelanggan yang berminat menggunakan jasanya lalu memberikan katalog cetak untuk melihat paket-paket jasa yang ada pada Sheen Production. Hal ini dirasa kurang efektif untuk penulis yang membuat penulis membuat sebuah media promosi berbentuk katalog digital. Katalog merupakan media promosi yang digunakan perusahaan untuk memudahkan konsumen dengan memberikan daftar gambaran produk yang ditawarkan perusahaan secara rinci ${ }^{[1]}$. Yang dimana katalog digital ini bisa dilihat dan mudah diakses melalui handphone dimana dari katalog digital ini akan memudahkan tim dari Sheen Production dan pelanggan.

Pengaruh media katalog digital ini tentunya diharapkan dapat memberikan pengaruh bagi pelanggan. Pelanggan dapat mengetahui informasi tentang jasa fotografi dan videografi seperti paket yang ditawarkan, harga dan contoh dari hasil jasa fotografi dan videografi tersebut dengan mudah melalui handphone. Penulis ingin membuat sebuah media promosi berbentuk katalog digital yang diyakini menghemat biaya pencetakan katalog serta meningkatkan efisiensi dalam menampilkan paket harga yang ditawarkan di dalam katalog digital.

\section{METODE PENELITIAN}

Dalam penelitian ini menggunakan metode mind mapping untuk memudahkan penulis dalam mengingat suatu informasi utama dan juga dalam perancangan desain katalog digital dengan menggunakan konsep desain yang terdiri dari layout kasar, layout komprehensif dan final artwork. Berikut adalah mind mapping dalam penelitian saya:

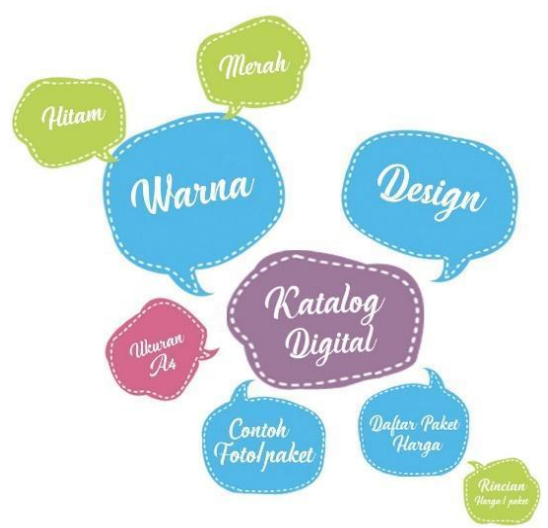

Gambar 1. Mind Mapping

\section{LITERATURE REVIEW}

Berikut ini adalah literature review yang berkaitan dengan topik penelitian yaitu desain media katalog digital :

Penelitian yang dilakukan oleh Indah dan Dwi Sudjanarti $(2018)^{[2]}$ dengan judul "Desain Katalog Digital Sebagai Media Promosi Menggunakan Aplikasi Coreldraw X7 Dan Flipbook Maker Pada Pusar Creative Malang” Penelitian ini menyimpulkan bahwa media promosi yang 
telah digunakan hanya menampilkan beberapa informasi produk yang terbatas. Maka dari itu katalog digital dibuat dengan tujuan untuk memberi informasi produk secara detail beserta cara pengemasan yang dikemas secara menarik.

Penelitian ini dilakukan oleh Susana (2020) ${ }^{[3]}$ dengan judul "Perancangan E-Katalog Produk Berbasis Android Pada Pt. Samudera Jaya Benelli Menggunakan Metode User Centered Design (UCD)". Penelitian ini menghasilkan e-katalog yang berguna dan efektif dalam melakukan penjualan pada PT. Samudera Jaya Benelli, dan dapat menghemat biaya pencetakan system yang tadinya dipakai secara manual sekarang diwujudkan secara digital.

Penelitian yang dilakukan oleh Afis dan Tri Handayani (2020) ${ }^{[4]}$ dengan judul "Peran Promosi Melalui Iklan Katalog Dalam Keputusan Pembelian Konsumen (Studi Kasus Pada Minimarket Indomaret Di Kota Bengkalis)". Penelitian ini membuat peningkatan pada keputusan pembelian dari tingginya pengaruh iklan katalog pada Minimarket Indomaret.

Penelitian ini dilakukan oleh Bawaiqki, dkk (2020) ${ }^{[5]}$ dengan judul "Perancangan Media Katalog Sebagai Penunjang Promosi Dan Informasi Pada Pt. Citra Surya Selaras". Penelitian ini menghasilkan media desain katalog yang kreatif agar terlihat menarik, desain dibuat dengan layout, warna yang jelas dan simple, gambar dan teks yang berisi informasi keunggulan dan produk pada PT. Citra Surya Selaras Kota Tangerang.

Penelitian ini dibuat oleh Setyanti dan Umi Khabibah (2017) ${ }^{[6]}$ dengan judul "Aplikasi Adobe Photoshop Cs6 Pembuatan Desain Katalog Sebagai Media Promosi Di Cv Kajeye Food Malang”. Di dalam penelitian ini menghasilkan media katalog untuk meningkatkan kegiatan promosi pada CV Kajeye Food Malang menggunakan aplikasi Adobe Photoshop CS6, kemudian katalog ini dibagikan kepada 10 responden yang mendapatkan hasil yang menunjukan bahwa katalog CV Kajeye Food Malang ini sangat efektif dan layak digunakan dan dipublikasikan sebagai media promosi.

\section{HASIL DAN PEMBAHASAN}

\subsection{Konsep Perancangan}

Perancangan katalog digital memiliki beberapa konsep perencanaan, yaitu:

\subsubsection{Perencanaan Media}

Untuk meningkatkan minat pelanggan melalui katalog digital sebagai media penunjang informasi dan promosi pada Sheen Production, yang diterapkan sebagai media digital yang didalamnya terdapat unsur seperti logo, warna, desain serta foto sehingga terlihat menarik secara visual.

\subsubsection{Perencanaan Konsep}

Perencanaan konsep ini pada setiap lembar katalog memiliki unsur warna, teks, dan foto hasil fotografi serta angka dan terdapat logo Sheen Production untuk menarik secara visual dimata pelanggan.

\subsubsection{Perencanaan Visual}

Dalam pembuatan katalog digital diberikan sebuah nuansa yang baru berupa foto hasil fotografi, perpaduan warna yang sesuai dengan Sheen Production, desain yang dibuat dengan simple, menarik, menghibur dan isi pesan yang ingin disampaikan dapat tercapai ke masyarakat, dan desain yang dibuat bermanfaat ${ }^{[7]}$. beberapa elemen desain dan logo dari Sheen Production sehingga menjadikan sebuah katalog digital yang bernilai dan informatif.

\subsection{Tujuan Kreatif}

Tujuan kreatif pembuatan katalog digital pada Sheen Production untuk meningkatkan minat serta keefektifan dalam penyampaian informasi dan promosi sehingga dapat menaikan citra dari Sheen Production. Dan juga agar audience bisa membaca dengan mudah informasi yang diberikan dari desain yang dibuat ini ${ }^{[8]}$. 


\subsection{Layout Kasar}

Layout Kasar berupa sketsa atau ide/gagasan sebagai sebuah dasar desain media. Layout Kasar dalam bentuk coretan-coretan atau sketsa yang umumnya dibuat dengan warna hitam dan putih menggunakan pensil gambar. Berikut adalah layout kasar yang dibuat:
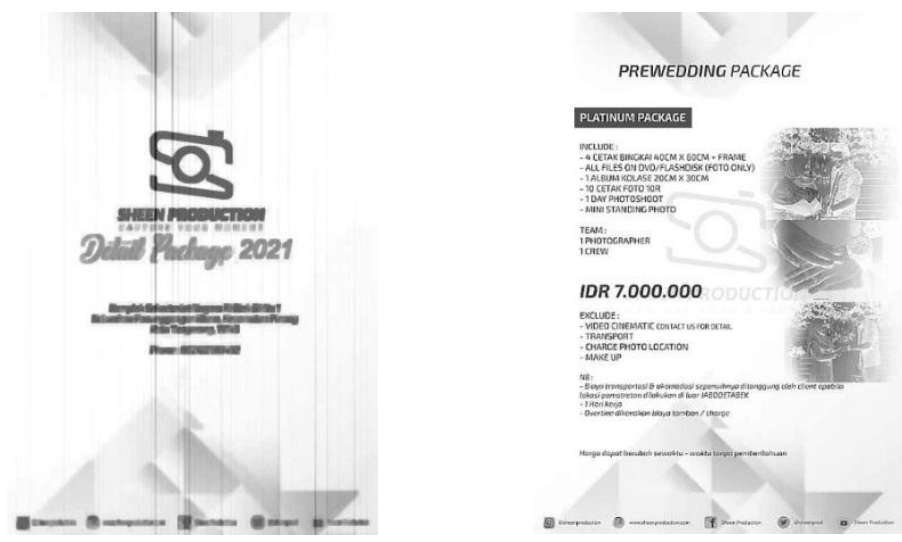

Gambar 2 dan 3. Layout Kasar Cover Katalog dan Prewed Platinum Package.
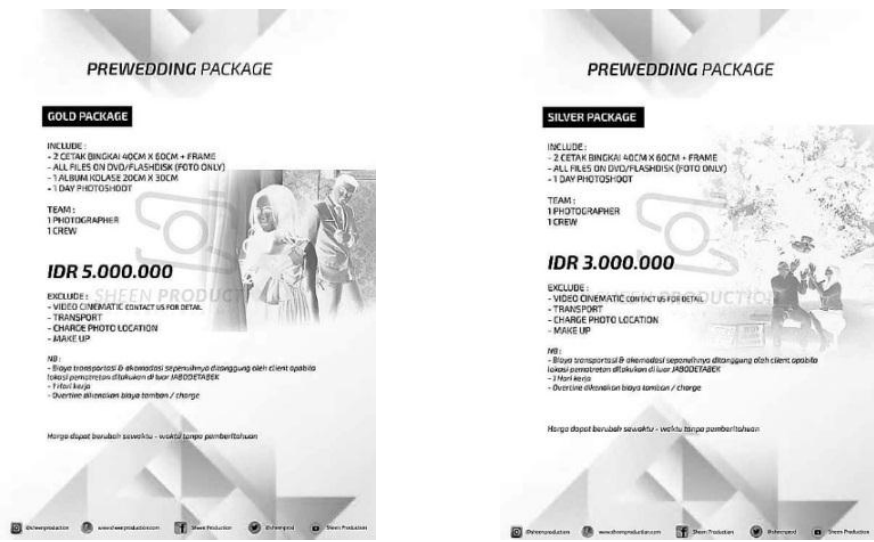

Gambar 4 dan 5. Layout Kasar Prewed Gold Package dan Prewed Silver Package
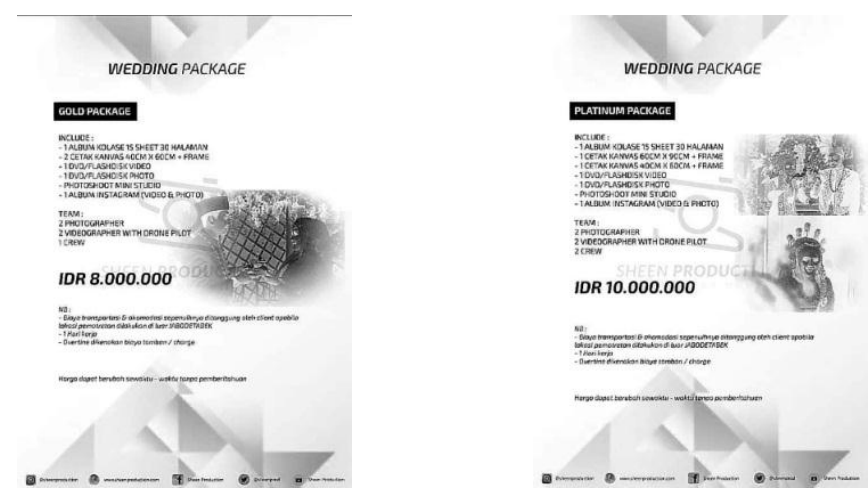

Gambar 6 dan 7. Layout Kasar Wedding Platinum Package dan Wedding Gold Package 


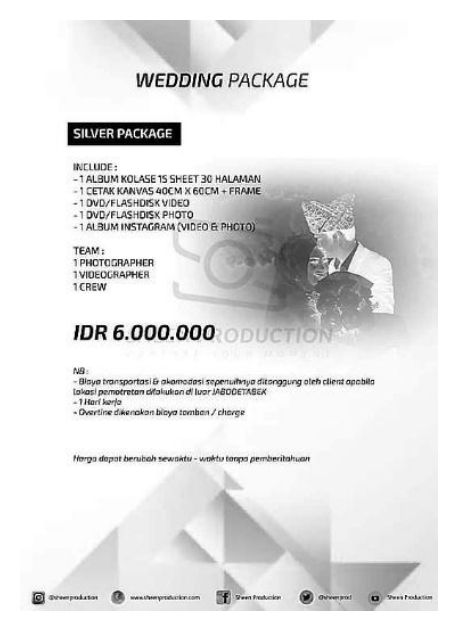

Gambar 8. Layout Kasar Wedding Silver Package

\subsection{Layout Komprehensif}

Layout Komprehensif adalah proses desain yang sudah memasuki tahap komputerisasi dan pewarnaan, namun tahap ini belum selesai seutuhnya, karena masih harus mengalami proses revisi ${ }^{[9]}$. Layout Komprehensif ini dibuat dengan menggunakan aplikasi Photoshop CC 2019. Berikut adalah Layout Komprehensif yang dibuat:
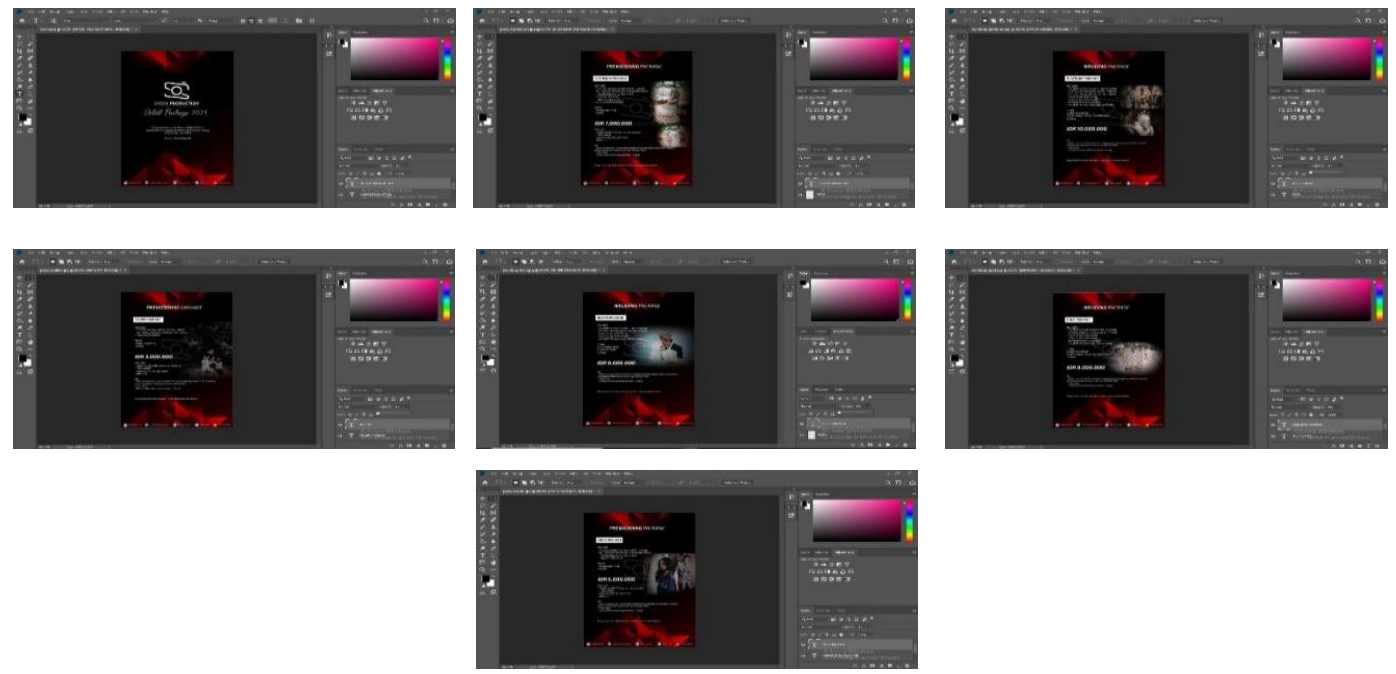

Gambar 9. Layout Komprehensif Katalog Digital 


\subsection{Final Artwork}

Final Artwork adalah istilah untuk file-file desain akhir yang siap untuk dicetak ${ }^{[10]}$. Final Artwork inilah yang akan ditampilkan di dalam katalog digital Sheen Production:

- Cover Katalog Digital Sheen Production

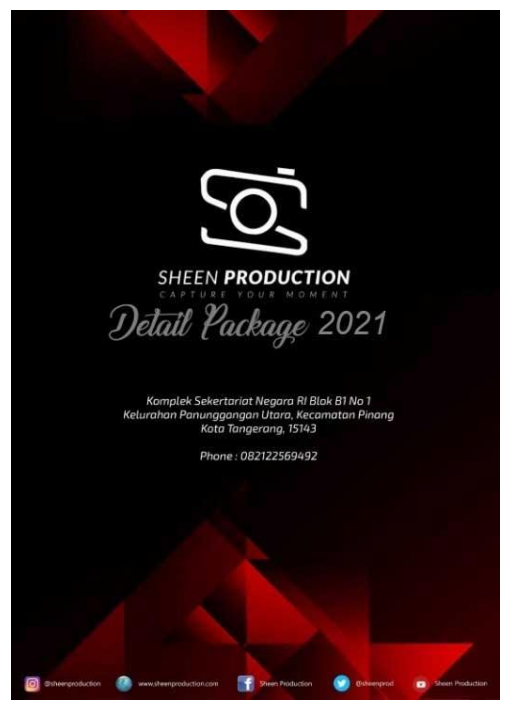

Gambar 10. Final Artwork Cover Katalog Digital.

Pada Gambar 10 diatas merupakan desain cover katalog digital yang terdiri dari judul katalog, logo, alamat, serta terdapat alamat sosial media dari Sheen Production. Ukuran kertas A4, menggunakan warna merah dan hitam, dengan menggunakan fonts Eastman Grotesque, Calibri, dan Back to Black Demo.

- Halaman Pertama: Pre Wedding Platinum Package

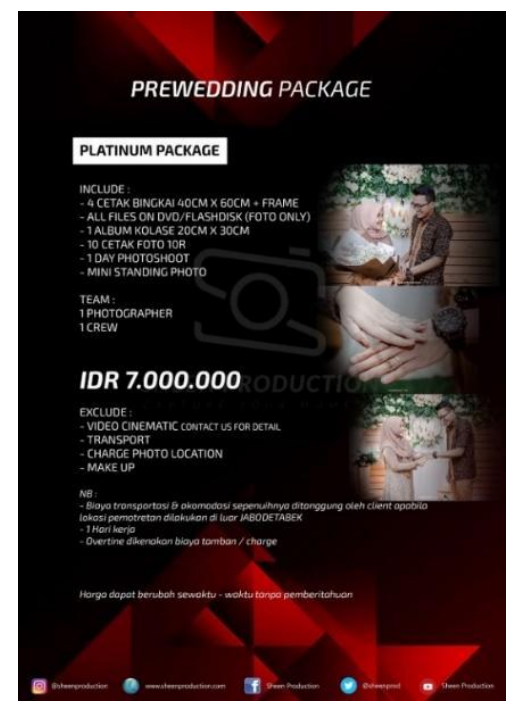

Gambar 11. Final Artwork Prewedding Platinum Package Katalog Digital

Pada Gambar 11 diatas merupakan lembar pertama Prewedding Platinum Katalog Digital yang terdiri dari judul package, deskripsi dari yang didapat dalam paket platinum, harga paket, serta terdapat alamat sosial media di bagian bawah, menggunakan ukuran 
kertas A4 dengan menggunakan warna merah dan hitam, serta memakai fonts Eastman Grotesque, dan Calibri.

- Halaman kedua : Pre Wedding Gold Package

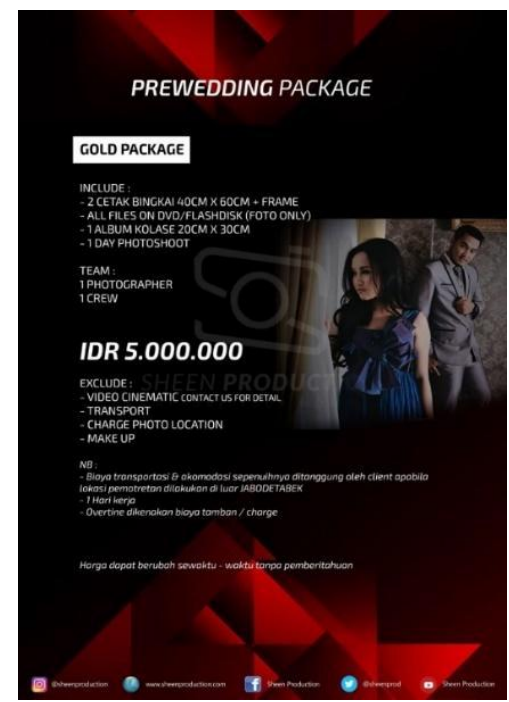

Gambar 12. Final Artwork Prewedding Gold Package Katalog Digital

Gambar 12 diatas merupakan lembar kedua dari katalog digital yang berisi tentang detail prewedding gold package seperti judul package, nama paket, detail isi paket, harga paket, dengan menggunakan ukuran kertas A4, memakai warna merah dan hitam, serta menggunak fonts Eastman Grotesque, dan Calibri.

- Halaman ketiga: Pre Wedding Silver Package

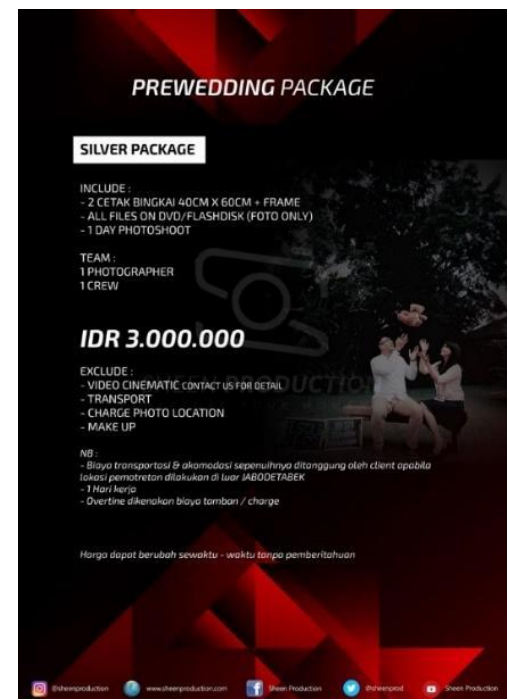

Gambar 13. Final Artwork Prewedding Silver Package Katalog Digital

Gambar 13 diatas merupakan lembar ketiga Prewedding Silver Katalog Digital yang terdiri dari judul package, deskripsi dari yang didapat dalam paket silver, harga paket, serta terdapat alamat sosial media di bagian bawah, menggunakan ukuran kertas A4 dengan menggunakan warna merah dan hitam, serta memakai fonts Eastman Grotesque, dan Calibri. 
- Halaman keempat: Wedding Package Platinum

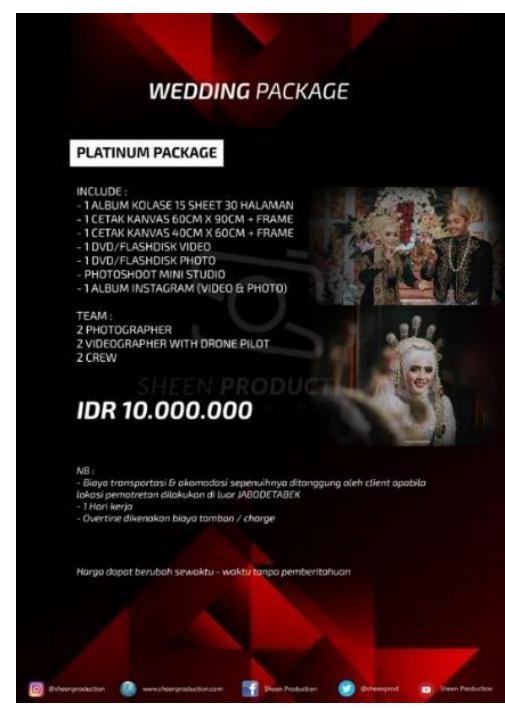

Gambar 14. Final Artwork Wedding Platinum Package Katalog Digital

Gambar 14 diatas merupakan lembar keempat Wedding Package Katalog Digital yang terdiri dari judul package, deskripsi dari yang didapat dalam paket platinum, harga paket, serta terdapat alamat sosial media di bagian bawah, menggunakan ukuran kertas A4 dengan menggunakan warna merah dan hitam, serta memakai fonts Eastman Grotesque, dan Calibri.

- Gambar kelima: Wedding Gold Package

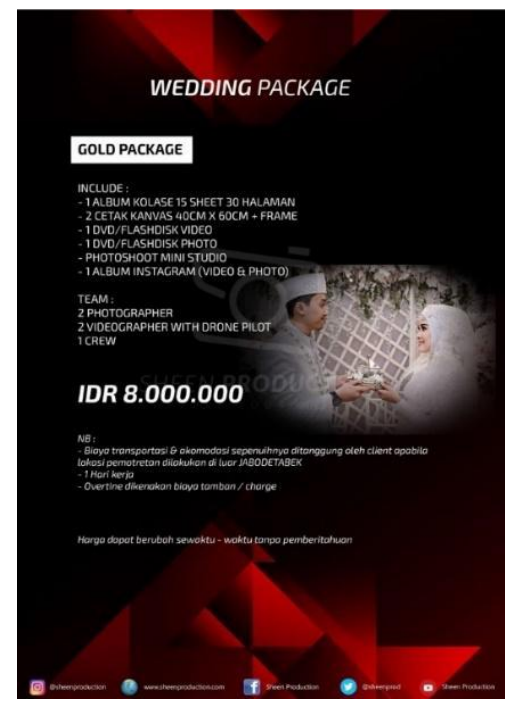

Gambar 15. Final Artwork Wedding Gold Package Katalog Digital

Gambar 15 diatas merupakan lembar kelima Wedding Gold Package Katalog Digital yang terdiri dari judul package, deskripsi dari yang didapat dalam paket gold, harga paket, serta terdapat alamat sosial media di bagian bawah, menggunakan ukuran kertas A4 dengan menggunakan warna merah dan hitam, serta memakai fonts Eastman Grotesque, dan Calibri. 
- Lembar keenam: Wedding Silver Package

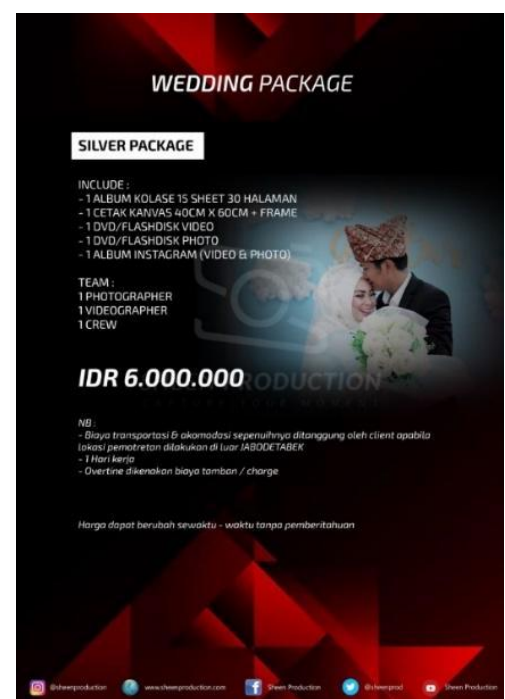

Gambar 16. Final Artwork Wedding Silver Package Katalog Digital

Gambar 16 diatas merupakan lembar keenam Wedding Silver Package Katalog Digital yang terdiri dari judul package, deskripsi dari yang didapat dalam paket silver, harga paket, serta terdapat alamat sosial media di bagian bawah, menggunakan ukuran kertas A4 dengan menggunakan warna merah dan hitam, serta memakai fonts Eastman Grotesque, dan Calibri.

\section{KESIMPULAN}

Perancangan media penunjang promosi dan informasi pada Sheen Production dalam menarik pelanggan tentunya harus ada media pendukung dan ciri yang melambangkan identitas. Media promosi dan informasi yang efektif untuk menginformasikan dan mempromosikan dapat seperti katalog digital ini sangat besar pengaruhnya dalam menyampaikan pesan dan informasi secara efektif tanpa perlu mengeluarkan biaya untuk cetak katalog.

Katalog Digital sangat berfungsi dalam mendukung pemasaran atau promosi, untuk meningkatkan pelanggan baru. Apalagi dalam bentuk digital yang memudahkan dalam berbagi dengan cepat dan mudah melalui media yang sudah di sediakan di era digital ini. Serta tampilan foto dan harga yang dicantumkan secara kreatif yang dihasilkan dan ditata sesuai kebutuhan pelanggan.

\section{SARAN}

Saran untuk Sheen Production yaitu dengan media sosial yang sudah ada pada Sheen untuk diupdate dan disebar luaskan agar para customer mengetahui isi detail paket dan harga yang ada pada katalog agar tidak ada lagi ketidaktahuan para customer tentang informasi detail jasa yang ditawarkan. Dan juga harus lebih update apabila ada perubahan harga maupun detail dari paket setiap tahunnya. 


\section{DAFTAR PUSTAKA}

[1] Mubarok, 2019. Perancangan Multimedia Interaktif Company Profile Dan Katalog Produk Sebagai Media Promosi Zie Batik Semarang.Semarang: UNNES.

[2] Indah, Vivi Safitri dan Dwi Sudjanarti, 2018. Desain Katalog Digital Sebagai Media Promosi Menggunakan Aplikasi CorelDraw X7 dan Flipbook Maker Pada Pusar Creative Malang, JAB Jurnal Aplikasi Bisnis Vol.4 No.1, Malang, Politeknik Negeri Malang.

[3] Susana, 2020. Perancangan E-Katalog Produk Berbasis Android pada PT. Samudera Jaya Benelli Menggunakan User Centered Design (UCD), METIK Vol.4 No.2, Pontianak, Universitas Widya Dharma Pontianak.

[4] Afis dan Tri Handayani, 2020. Peran Promosi Iklan Katalog dalam Keputusan Pembelian Konsumen (Studi Kasus Pada Minimarket Indomaret di Kota Bengkalis), Jurnal Ekonomi dan Manajemen Teknologi Vol.4 No.2, Riau, Politeknik Negeri Bengkalis.

[5] Bawaiqki, Anita Wandanaya, Eric Febriyanto, dan Devi Iswara, 2020. Perancangan Media Katalog Sebagai Penunjang Promosi dan Informasi Pada PT. Citra Surya Selaras, MAVIB Journal Vol. 1 No.1, Tangerang, Universitas Raharja.

[6] Setyanti, Nugraheni dan Umi Khabibah, 2017. Aplikasi Adobe Photoshop CS6 Untuk Pembuatan Desain Katalog Sebagai Media Promosi Di CV KAJEYE FOOD MALANG”. JAB Jurnal Aplikasi Bisnis Vol. 3 No. 2, Malang, Politeknik Negeri Malang.

[7] Maimunah dan Rifki Adi Syahputra, 2018. Desain Media Informasi PT. PLN (Persero) Distribusi Banten, CCIT Journal, Vol.11 No.2, Tangerang, STMIK Raharja.

[8] Triyono, Kemal Salahuddin, dan Hendi Setiawan, 2017. Desain Media Komunikasi Visual Penunjang Event Wisuda, CCIT Journal Vol. 10 No. 1, Tangerang, STMIK Raharja.

[9] Maulani, Giandari, Siti Nur Janah dan Alam Mahbubi 2017, Desain Media Komunikasi Visual Berbentuk Tabloid Sebagai Sarana Promosi SMK Mandiri 2, Jurnal Ilmiah SISFOTENIKA Vol.7 No.1, Pontianak, STMIK Pontianak.

[10] Sulaiman, Annas Marzuki dan Sugiyanto 2019, Optimalisasi Potensi Karya Mahasiswa Mata Kuliah Grafika DKV Melalui Galeri Online, Journal of Art, Design, Art Education And Culture Studies, Vol.4 No.1, Malang, Universitas Negeri Malang. 